\title{
Parents' Involvement and Perspectives Towards the Quality of Teaching: A Review of Related Literature
}

\author{
Manal Alshammari ${ }^{1, *}$ \\ ${ }^{1}$ Kingdom of Saudi Arabia \\ *Correspondence: E-mail: manal2468@yahoo.com
}

Received: April 15, 2017 Accepted: April 27, 2017 Published: May 23, 2017

doi:10.5296/ije.v9i2.11068 URL: https://doi.org/10.5296/ije.v9i2.11068

\begin{abstract}
In this paper, I discussed the main findings and assumptions posited for the related literature on the parental involvement. Firstly, I discussed the definition of parental involvement. Secondly, I discussed a brief historical background of parental involvement with special reference to its status in the UK. Thirdly, I discussed the effectiveness of parental involvement in the learning process in addition to the factors that encourage parents to get involved in their children's education and its importance. Fourthly, I investigated the counterarguments advanced against parental involvement and when it becomes negative, most notably overparenting. Fifthly, this section discussed the barriers that prevent parents from getting involved in their children's education, including the parent and family factors, child's age, learning difficulties and disabilities, behaviour problems of the children and the asocial factors, such as poverty. In the last section of this chapter, I discussed the school-relayed factors that affect parental involvement like the school culture as well as the location of the school
\end{abstract}

Keywords: Parents' involvement; quality of teaching; schools; Saudi Arabia 


\section{Introduction}

Surveying the related literature, it is obvious that the quality of teaching has been the focus of a substantial bulk of research. That is because the teaching quality plays an important role in enhancing students' academic progress and consolidating the interrelationship between the students and their teachers, on the one hand, and the students' parents and school staff including teachers, on the other (Felder \& Brent 1999). With strong interrelationships between students, parents, and school staff, students are much more encouraged to listen to their teachers and try their best to please their parents and staff with high academic progress (Ingersoll \& Kralik 2004). In this respect, Cohen \& Brown (2016) argued convincingly how school settings become suitable environments for students to learn when teachers have good relationships with students' parents. A further line of research has centred on the factors that have impacts on the teaching quality, such as parents' involvement and perspectives towards the quality of teaching.

The importance of parents' involvement and perspectives towards the quality of teaching is that the former is a reflection to the latter, given that when the parents are happy with their child progress at school, it is most likely that the teaching quality in their children's school is high (cf. Hoover-Dempsey et al. 2001 and Dang 2015, among others). The reverse is true- when the students' parents have concerns about their children's progress, it is most likely that the teaching quality at their children's schools is insufficient and needs more improvement. That is because parents do not often have such concerns only when their child's academic progress is decreasing, a matter which might reflect poor teaching quality at school. (cf. HooverDempsey et al. 2005).

Other researchers argued that parents' involvement and perspectives towards the quality of teaching is vital not only in mirroring the educational situation and teaching quality, but also in enhancing teaching and students' academic progress. The argument is, as referred to above, that as the parents are people with more contact with their children, they can determine the main aspects of their child's character and even the best methods to deal with him/her'. In addition, parents are an important aid to the teachers to help their child proceed and bolster his/her success through encouraging them do their homework and work cooperatively with the teachers when tackling the weak aspects of their children's academic progress (Oakes et al, 2015). In next subsections, I shed light on the major studies that have been conducted on the parents' involvement and perspectives towards the quality of teaching. I report their methods as well as findings. It will become clear that parents' involvement and perspectives towards the quality of teaching has never been conducted as far as KSA (my home country where this data of study is collected) is concerned.

\section{Parents' Involvement: Definitions and Related Issues}

One look at the related literature, it is quite clear that there is a plenty of terms and concepts that have been utilized to refer to the cooperation between schools (represented by school principals and teachers) on the one hand and children's parents on the other. Of these terms and concepts are parental involvement, parental participation, educational partnership, and school- 
family relations, among others (Driessen et al 2005). Due to a broad line of research investigating parental involvement, one can single out certain categories or factors that are related to parental involvement. In this regard, Grolnick and Slowiaczek, (1994) made clear that there are three aspects which must be taken into consideration when parental involvement is investigated, namely parents' behaviour in the sense that they take part in the school activities, personal involvement in the sense whether the parents can provide a suitable environment for their child progress, and parents' intellectual involvement in that whether the parents can expose their child to cognitively stimulating activities (see Huntsinger \& Jose, 2009 for more details and analysis).

A further line of research has indicated that there are three different aspects which must be taken into account for a better definition and description of parental involvement (cf. AbdulAdil, \& Farmer 2006, p.2). The first aspect is the so-called the attitudinal components of parental involvement. In this aspect, the most important factors include parents' aspirations as well as expectations of their children. Here, it is important to define parental involvement with reference to which factors trigger such involvement, most notably, the parents' expectation towards their child's academic progress. The second aspect is associated with the behavioural components of parental involvement. In this aspect, it is vital to explore whether parents assist their children with their homework and cooperate effectively with teachers and other school staff, especially in the parent-teacher conferences. In the third aspect, the main focus is placed on the so-called general parenting style or parent-child interactions. Here, it is important to figure out the actual interaction between parents and their children with respect to the school life and work out which ways this interaction can be developed so as to yield better outcomes and make the parental involvement effective (Abdul-Adil \& Farmer 2006).

In view of this, parental involvement is not easy to pin down or defined in terms of the aspects related to it. This assumption has been reiterated several times in pertinent studies that attempted to investigate parental involvement and furnish a suitable definition for it (HooverDempsey et al. 2001 and Shumow \& Hiatt-Michael 2010). In a related vein, Harris and Goodall (2006) postulated that the interleaving nature of the parental involvement caused different understandings of the concept of parental engagement. Conteh and Kawashima (2008) assume that parental involvement subsumes a multitude of activities which are difficult to include under one umbrella, given that such activities are conceived differently by the parents and school.

Accordingly, parental involvement is clearly a complex term, which is hard to define (Wilder 2014). That is because this type of involvement must be construed with reference to parents, school and even the community. However, this complexity of parental involvement does not block researchers to suggest definitions for it. One of the most common definitions of parental involvement is attributed to Hill et al (2004), who defined parental involvement as interactions from the parents with their children, which allow the children to get benefit from the educational outcomes and future success of the students. Hornby (2011) assumed that parental involvement is a type of interaction that includes several contributions and practices by parents. Such contributions and practices contain parental home-based involvement, including their support to enhance their child's language skills as well as supervision of their children's 
homework. Additionally, such contributions and practices contain parental school-based which may also extend to parents' participation in the support of lessons (e.g. listening to children read), support on educational visits, involvement in Parent Teacher Associations and on school governing bodies. For the purposes of the current research, it is parental school-based involvement which is important. I leave parental home-based involvement open for further research as far as Saudi schools are concerned.

What is relevant here is Epstein's $(1992,2001)$ and Epstein et al (2002) studies that have distinguished six types of parental involvement. These types include parenting, communication, volunteering, home tutoring, involvement in decision-making, and collaboration with the community. Epstein's research suggests "that when parents participate in their children's schooling, students may experience more academic and social success. Stelmack (2005) mentions that Epstein's research shows that parental involvement can have a positive impact on student's academic work. Epstein suggests that parents who are informed and involved in their children's school can positively impact their child's attitude and performance. Parents' awareness and interest in their children's learning and school activities models for their children the importance of school, which may lead to positive behaviours."

The following is a short description of these six types of parental involvement and how the school must respond to them, as reported in Hornby and Lafaele (2011, p.38):

1. Parenting: schools must help parents with the creation of positive home conditions to promote the development of children. Parents must prepare their children for school, guide them and raise them.

2. Communicating: schools must inform parents about the school programme and the progress of children's school careers. Schools must also present such information in a manner which is comprehensible to all parents, and parents must be open to such communication.

3. Volunteering: the contribution and help of parents during school activities (e.g. reading mothers and fathers, organisation of celebrations).

4. Learning at home: activities aimed at the support, help and monitoring of the learning and development activities of one's school-going children at home (e.g. help with homework).

5. Decision making: the involvement of parents in the policy and management of the school and the establishment of formal parental representation (e.g. school board or parent council memberships).

6. Collaborating with the community: the identification and integration of community resources and services with existing school programmes, family child-reading practices and pupil learning.

One remark is in order before closing off this section. One might ask about the definition of the word 'parent'. Here, I make recourse to Hornby's (2011, p.1) definition of the word 'parents'. Hornby (2011) defines the word 'parents' as any person, who is undertaking the job of carrying out the parental role for the children. As such, parents include mother, father, grandparents or even any family member or anyone who is acting as a guardian for the children 
at school.

In the next subsection, I shed light of the history of the concept of parental involvement in the UK. This history provides us with a brief but insightful background on the actual nature of parental involvement and the extent to which this type of school-parent interaction is important for the children's progress and the quality of teaching.

\section{Parental Involvement: A Brief Chronological Background}

Given its direct consequences on the educational outcomes as well as students' progress, parental involvement has received attention since the second half of the last century, epically when research has begun investigating the aspects that affect education and lie beyond school boundaries (Smit 1993). For example, the interest in parental involvement has been much highlighted in the UK when the Department of Education and Science (DES) has identified in 1967 the significance of this type of involvement (cf. Hornby 2011, p.1). Additionally, the USA policy of 'No Child Left Behind' and the UK equivalent 'Every Child Matters' encouraged parental involvement in schools in the USA and UK, respectively. Since then, many works have shifted the interest towards investigating the effects of parental involvement and the ways by which it can be developed or used as a successful tool to bolster the educational process and education efficacy across the countries (Hornby ibid).

Therefore, parental involvement is not considered a new concept or phenomenon whose aspects are still unclear. On the contrary, parental involvement had been a research locus with a substantial bulk of research results and recommendations. The related studies and research have shown the numerous benefits of getting parents involved in their children's learning process. Recognising the importance of this involvement, the legislation in the UK has supported it through a set of instructions and regulations that were meant to encourage parents to take part in the learning process in a systematic way (Desforges \& Abouchaar 2003). In this connection, Plowden (1967) highlighted the influence of parental attitudes in academic progress, as one instance of the long appreciation of the role of effects of parental involvement. Furthermore, one conclusion of this long tradition in investigating parental involvement has been the assumption that it is one of the essential elements which are used to achieve improvement in education (even for students with higher ages). To make the partnership between teachers and parents real and closer to the child's learning is a repeated conclusion and a welcome result. Additionally, the assumption that increasing parental encouragement can effectively enhance academic progress when it is properly applied and mentored has been one of the signposting conclusion in the relation between schools and parents and encouraging the local governments to launch specialized programs to enrich such a relation (cf. Desforges \& Abouchaar 2003).

In 1984, the British Government issued the so-called 'Green Paper', which aimed to push parents to be represented in school governing bodies. In 1989, the British Education Act capitalized the underlying role of parents in their children's' education, stressing at the same time parents' involvement in children's assessment and their representation in governing educational bodies (Gezani 2009, p.16). These two motions clearly show the recognition of the 
British government in highlighting the role of parental involvement and the ways by which it can be bolstered (Williams et al 2002, p.2). After that, there were several steps taken by the British government to enhance parental involvement in schools in a systematic way. These include the British government guidelines in (1997) to maximise the need to make the parents involved in school, a matter which is conceived as important in securing a greater wellbeing and higher attainments for young people (Harris et al 2009). In addition, such steps include Ofsted organisation works regarding how a school could be effective in engaging parents with school decisions. The main gist of this program was to create 'a positive interaction with parents, the quality of communications, reporting to parents on progress of the students' academic progress and the mechanisms for helping parents to support their children's learning' (Goodall \& Vorhaus 2011, p.16). In the next subsection, I elaborate more on the effective aspects of parental involvement, discussing how this involvement helps enhance the learning process.

\section{Effectiveness of Parental Involvement in Learning Process}

Grolnick and Slowiaczek (1994), Hallgarten (2000), and Anderson and Minke (2007) made it clear that the relation between schools and parents is not so straightforward. Such a relation can help build success and prosperity in terms of learning process, but it can destroy such success and prosperity and thus have detrimental effect on the learning process. Such an unclear relation has brought a substantial line of analysis to investigate the actual interaction between parents and the schools and explore to which extent parental involvement can lead to positive effects on the school and the learning process in general. When the partnership between home and school is positive, it turns out as an influential factor that can enhance school efficiency as well students' progress (cf. Hallgarten 2000 and Ofsted 2000).

In this regard, Harris et al (2009) argued that the school and home are not similar but two completely different worlds for children and younger students. The two worlds (environments) can affect students' perspectives towards the other environment in many different ways. For instance, when the students receive support as well as encouragement from their parents at home, they will feel better and interact with other students in a proper manner in the school. This gives rise to the assumption that parental involvement can trigger students to perform better as long as such involvement is meant to support the students and encourage them. On the other hand, Harris et al (2009) assumed that parental involvement is sometimes difficult to control and hence might lead to negative effects on the school and teachers. Therefore, Harris et al (2009) recommended that parental involvement is effective and can be used as a suitable and influential device to support students, but it must be used in a careful way.

What is most relevant here is Harris et al's (2009) assumption that as long as the parents are aware of their engagement in school being a part of their role towards their child, they will be more responsible for such a role, and their parental involvement, as a result, will be effective. Harris et al (2009) assume that parental engagement in the schools can lead to plenty of remarkable outcomes on their children's achievement and progress. This being the case, Harris et al's (2009) concluded that parents have an influential role in promoting the educational levels 
in general. Moreover, Harris et al (2009) assumed that there is a robust correlation between parental involvement and students' academic achievement; hence, this type of involvement must be taken into consideration in any plan to enhance students' progress and school efficiency.

In a related vein, Grant and Ray (2010) argued that parental involvement is very important for the students and school developments. They showed that schools which support and encourage parental involvement are successful, and that the students exhibit better academic progress as compared to the schools which do not support parental involvement of the students' family (see Hornby 2011, p.2 for full details on this point). Grant and Ray's (2010) study is thus evidence for the fact that parental involvement is not only important for the students, but is also important for the schools and their development. Additionally, Grant and Ray's (2010) study implies that schools could have a vital part and role in encouraging the parent to get involved to communicate with the school, in addition to guiding the students to perform better and achieve the best academic progress their parents want.

By the same token, Hornby (2011) argued that parental involvement can result in several positive points and benefits for parents, children, and teachers alike. Hornby (2011) assumed that parental involvement helps the parents to increase their confidence, self-esteem, satisfaction and interest in their children's education. With regard to the children, Hornby (2011) assumed that parental involvement can enhance their behaviour, attitude, social life, attendance and even the mental health by virtue of the support they receive from the school and their parents. Concerning the teachers, Hornby (2011) assumed that parental involvement can enhance the partnership between parents and teachers, in addition to increasing teacher's morality in that the teacher becomes much loyal to the mission to of the school and working hard to enhance the students' academic progress. Additionally, parental involvement can lead to a more positive school environment which is necessary for students' success and teachers' distinction.

Furthermore, Hallgarten (2000) argued that parental involvement in the educational process and schools leads to several benefits for the whole community. That is because it consolidates the partnership between schools and parents as being active members in the community. Parents' views towards the school and collaboration between them are important in securing a communal environment, where the school can function effectively. On the other hand, Hallgarten (2000) made it clear that parental involvement might have some disadvantages when it drifts away from its main objectives or when it is misapplied. Hallgarten (2000) assumed that parental involvement could affect badly the children whose parents are not involved in the school. In other words, parental involvement can impinge badly on other students with no supervision on the part of their parents. The question is how these negative effects appear. The answer lies in the fact that it is probable that teachers pay more attention to the children whose parents are involved. Consequently, other students whose parents are not involved in schools and do not ask about their children can be negatively affected in that no attention or enough attention is paid to them. Thus, parental involvement may create negative impact on other students as long as the teachers do not ensure equal attention for all children, irrespective of whether their parents are involved or not in the schools.(Note 1) 
Surveying the related literature, there are several research papers that shed light on the negative impacts of the parental involvement, either such impacts are direct or indirect (Milne et al 1986, Fan 2001 \& Domina 2005, p.234). Some other researches including Keith (1991), Muller (1993), and Singh et al (1995), Ho and Willms (1996), Miedel and Reynolds (1999), and Crosnoe (2001), reported that the effectiveness of parental involvement is in the first place contingent on which aspects of involvement are considered and which educational outcomes are intended (cf. Domina 2005, p.234). Hence, the parental involvement does not have a fixed effect on the education, but rather it is sensitive to several aspects which can be taken into consideration.

Moreover, Fan and Chen (2001) point out that students' educational achievement is much related with parental involvement as well as parent's expectations of their children's academic progress. However, Fan and Chen (2001) argued extensively that parents must have their 'local' role in supervising their children at home. Parents' positive expectations and parental involvement in school would assist in positively influencing the child's achievements, which could be as a moral encouragement. However, if there is no home supervision, parents' involvement can impact negatively on the children's academic achievement.

In this regard, Domina (2005) summarized two important aspects of parental involvement that affect its efficiency, namely the age of the students and the type of parental involvement activities. Firstly, Domina (2005) argued that students' age is a very significant factor that should be taken into account in parental involvement-related issues. Parental involvement might be more or less beneficial in some stages of students' life at school; hence, the assumption that the effects of parental involvement in one level does not extend to another. Domina (2005) assumed that the previous studies on parental involvement disregarded the elementary levels, and focused instead on high and middle levels where parental involvement is less common. Accordingly, the results drawn from these studies are not accurate enough if the generalizations over all levels are intended, given that they depend on one particular group age. Furthermore, Domina (2005) argued that the related literature on the effects of parental involvement have shed light on the implications of certain activities that have nothing to do with students' cognitive and educational achievements. What this implies is that parental involvement must be paired with suitable activities that affect the students' achievements, rather than encouraging the parents to be involved in the schools through activities which only ensure a permanent contact between the school and parents. What Domina (2005) alludes to is that schools encourage the parents to be partners of their children's' education. However, this encouragement is sometimes conducted through activities that do not impact positively on the students' cognitive and educational achievements.

This line of analysis gives rise to the assumption that causes of parental involvement must be separated from the effects of the parental involvement. The scholars who work on the effects of parental involvement made it clear that parental involvement does not always yield better results even if there are strong causes or triggers for it. There are several research papers that revealed the negative implications of parental involvement, which can lead to the so-called laid-back effects on the educational process (Huang \& Mason 2008). Laid-back effects refer to the situations whereby the students encounter problems, and their parents become more likely 
to get involved with teachers. While the students are succeeding, their parents become more relaxed with less desire for parental involvement. Hence, if there is any potential future lapse in students' academic progress, parents will have the desire to get involved in schools.

As I wrote earlier, some works have argued that parental involvement can have damaging effects on the students (in)directly. The students whose parents do not get involved in the educational process might be negatively affected. A further line of research has though indicated that parental involvement can negatively affect the same students whose parents do get involved in the educational process through the so-called over-parenting or 'helicopter parents'. Over-parenting refers to the situations whereby parents are over focused on their children. In this regard, Padilla-Walker and Nelson (2012) defined the term of helicopter parent as "high on warmth/support, high on control, and low on granting autonomy" (Padilla-Walker \& Nelson 2012; cited in Garst \& Gagnon 2015, p.8). There is some consensus that overparenting would passively affect the child because it yields anxiety, narcissism, and feelings of entitlement (see Wolfradt, et al 2003 and Segrin et al 2013). Over-parenting or helicopter parents leave detrimental effects on the students because they become over dependent, depriving the child of any motivation. Additionally, over-parenting or helicopter parents prevent the students from making their decisions and solving their problems on their own in the future (Garst \& Gagnon 2015, p.9). In this connection, Padilla-Walker and Nelson (2012) assumed that over-parenting or helicopter parents are triggered due to the pressures placed by children's parents to achieve academic success.

In the next section, I highlight the factors that trigger the parents to get involved in their children's schools.

\section{The Factors Behind Parental Involvement and Related Effects}

\subsection{Introduction}

Current research on the causes of parental involvement has referred to several factors that trigger the parents to get involved in their children's schools. Hughes, et al (1994) argued that factors that parents look for in a good school include: relationships between parents, teachers and children, the staff, the atmosphere, the ethos of the school, good discipline, wide-ranging education offered, the head-teacher, development of the whole child, and academic results. In addition, some pertinent research has found out that factors such as parents' race, ethnicity, and class background play a significant role in enticing the parents to ask for their children. For instance, the related literature argues that if the parents are from the middle class, they might have greater educational rewards for their involvement, as compared to the parents who belong to the poor class (Harris et al 2009, p.15). What is important to mention at this point is that this variance in parental involvement due to income might have negative effects on other students' educational achievements as referred to above, given that teachers might direct their attention towards the students whose parents are involved in the educational process. This being the case, we must take into account all of the consequences of parental involvement in addition to the related variables when assessing the extent to which parental involvement is successful (see 
Ho \& Willms 1996, Miedel \& Reynolds 1999, and Crosnoe 2001).

In view of this, parental involvement is necessary for students' academic and cognitive progress but it is not, on the other hand, sufficient to galvanize students' academic achievement in schools (Harris et al2009, p.15). Parental involvement is one of the factors that can enhance students' academic achievement in schools. There are other related factors which can develop students' achievements, even in cases where there is less parental involvement.

In the next section, I report the reasons that drive the parents not to get involved in the school and educational process.

\subsection{Parental Involvement: The Barriers}

Several studies investigating parental involvement have referred to certain factors which impact on the extent to which parents get involved in the educational process of their children as well as the types of parental involvement in schools (see Edwards \& Alldred 2000, Fan \& Chen, 2001, and Deslandes \& Cloutier 2002, among many others). These factors include parents and family factors, child-related factors (most notably age), learning difficulties and disabilities, behaviour problems, societal factors, etc. What follows sheds light on these factors, explaining how they affect the parents in getting involved in the schools.

\subsection{Parent and Family Factors}

Epstein (1990) and Hornby $(2000,2010)$ postulated that almost all of the parents do care about their children's education and progress irrespective of the background they come from. One of their major concerns circles around their children's education and around determining what factually the school expects from their children (i.e. whether the school is happy about their children's academic and cognitive level or not). Having said this, Epstein (1990) and Hornby $(2000,2010)$ argued that parental involvement is different depending on the parents' academic level as well (cited in Hornby 2000, p.4). The higher the academic level of the parents, the more they are inclined to get involved in the education of their children. In a related vein, Harris et al (2009) found out that parents' past experience is also an important factor that can encourage the parents to take part in their children's education. They argued that some parents strongly avoid any contact with their children's schools because of some negative experience or psychological problems they had in the past. Additionally, Harris et al (2009) concluded that some parents were not motivated to have participated in the school due to difficulties that emerge when dealing with the school environment. For instance, Harris et al (2009) showed that some schools have very comfortable settings, that ultimately encourage the parents to get involved in their children's school education, whereas other schools have messy settings (e.g. low school culture 'where beliefs and values that guide a school are not high) and less organization leading to discourage students' parents to practice any parental involvement. Furthermore, Harris et al (2009) mentioned that some parents abstain from any parental involvement practices because of the miscommunication between the teachers and school principal, on the one hand, and parents, on the other. They recommend that such schools should re-consider the way they communicate with parents and prepare for better meetings between the school and the parents. 
In the next subsection, I investigate the effect of children's age on parental involvement.

\subsection{Child's Age}

Hornby and Lafaele (2011) assumed that children's age can be a barrier to parental involvement, in the sense that parents are more interested in parental involvement as long as their child is younger. The argument is that parental involvement generally increases with younger children, and decreases with older ones. Hornby and Lafaele (2011) ascribed this to the parents' feeling that their younger child as he/she proceeds in age becomes more independent and so there is no point in parental involvement. Yet, Hornby and Lafaele's (2011) findings conflict with other earlier studies including Edwards and Alldred (2000) and Deslandes and Cloutier (2002), who argued that older students sometimes ask for parental involvement and parents are keener to get involved in their children's education (cf. Hornby \& Lafaele 2011, p.43).

\subsection{Learning Difficulties and Disabilities}

Seligman (2000) and Hornby and Lafaele (2011) hypothesised that children's academic progress could act as a barrier that hinders the parents from parental involvement. The idea is that parents are more inclined towards parental involvement and communicating with school teachers as long as their child has a disability or learning difficulties. This implies that parents are less involved in communicating with schools if their child does not have any disability or learning difficulties. By the same token, Seligman (2000) and Hornby and Lafaele (2011) argued that for many parents, it is more comfortable to get involved with the school as long as their child's academic progress and academic progress are high. Seligman (2000) and Hornby \& Lafaele (2011) found out that when parents think that their child is gifted, the former is more encouraged to get involved in school activities. This implies that parental involvement decreases as the child has bad academic progress (Hornby \& Lafaele 2011).

\subsection{Behavioural Problems}

Hirschi (1969) and El Nokali et al (2010) investigated the relation between children's behavioural problems and parental involvement. They assume that when the child has behavioural problems, parental involvement decreases. This can be ascribed to the fact that parents feel ashamed of their child and less willing to visit school because in doing so, they definitely avoid hearing more bad news. On the other hand, Chapple et al (2005, p. 359) defended the notion that parental involvement can help remedy children's behavioural problems, given that parents and teachers work with one another. The child's attachment to his/her parents is regarded as one of the overarching elements that nurture and enhance social bonds, helping students to avoid negative behaviour.

\subsection{Societal Factors}

In this section, I investigate the societal factors that impact on the extent to which parents take part in parental involvement.

Let us begin with the demographic factors. Drawing on the findings reached by Hornby (2000), it can be assumed that there are two demographic factors affecting parental involvement, namely parents' employment status and the split between the parents (divorce). Hornby (2000) 
found out that most of the parents who are working (i.e. employed) are less engaged in parental involvement. This so being, it can be postulated that 'work commitments' is considered a barrier against parental engagement (this does not imply that those parents who are unemployed have greater involvement either). In the same vein, Hornby (2000) and Hornby and Lafaele (2011) found out that it is not an absolute correlation that work has negative impacts on parental involvement. They rather show that it depends, in the first place, on the type of work the parent does and whether it is flexible that the parent can leave his/her work to ask about the children. As for the split between the parents, Hornby (2000) argued that when the parents are divorced, they are less likely to be engaged in parental involvement. In other words, a single parent does not get involved in his/her child's education. Similarly, Green et al (2007) points out that parents' level of education is another demographic factor that affect the extent to which parents are engaged in parental involvement of their children. The higher the parents' level of education, the higher the chance for them to be engaged in their children's education (see Hornby \& Lafaele 2011, p.41).

Moreover, Eccles and Harold (1993) had already pointed out that parental involvement is much affected by the psychological and medical status of the parents. Eccles and Harold (1993) showed that when the child's parent has a mental or health problem or bad physical status, he/she is less engaged in parental involvement and, if any, his/her involvement would not be effective. Further, Wanke (2008) argued that language is considered an important factor that can limit or enhance parental involvement. The assumption advanced is that when the family has another native language than the language that is spoken in school, less communication occurs between the family and the school, which in the end impinges on parental involvement.

In the next subsection, I investigate the school-related factors that affect parental involvement.

\section{The School-Related Factors That Affect Parental Involvement}

The related literature argued that parental involvement can be affected by some factors which are related to the school, including the school culture, the location of the school relative to the families' houses, and teachers' attitudes towards parental involvement, among others. In this section, I investigate some of these factors, attempting to show how such factors can affect or impinge on parental involvement.

\subsection{School Culture}

Several works have indicated that the school culture is a vital factor in parental involvement. It has been viewed even as the key to encourage parents to get engaged in their children's education (Hallgarten 2000 and Trotman 2001). In this regard, Hornby (2000) argued that as long as the school culture is more autocratic in the system and management, parental involvement is likely to be less active and the parents will be discouraged to get any role in parental involvement. Pertinently, Hallgarten (2000, p.3) discussed that some schools decide to exclude parents, and hence, less parental involvement. This is because of the fear that parental involvement might affect the system in the school. Trotman (2001) and Watson et al (2012) argued that the schools whose administration is autocratic tend to avoid parental 
involvement so as not to implement what the parents suggest.

\subsection{Location of School}

It appears that parental involvement would be facilitated as long as the school is located in a near location to the families (cf. Hornby 2000). On the other hand, some parents opt to select a school which is remote from their houses owning to the available facilities of the given school as well as its educational characteristics or fame. What this implies is that the location of the school is not a serious barrier that prevents or discourages parents from parental involvement if they have the actual intention to support their child. They can even change the school to a remote location for the sake of their child's future.

Teacher's attitude is regarded as an important aspect in encouraging/discouraging parental involvement. If teachers' attitude towards parental involvement is negative, there would not be any collaboration or communication between the two parties (Hornby 2000 and Wanke 2008). On the other hand, if teachers' attitude towards parental involvement is positive, there would be successful collaboration as well as communication between the two parties. See Bastiani (1989, reprinted 1995) Bastiani et al (2002), Crozier (1999), Inglis (2004), Nye et al (2006), Power and Clark (2000), and Walker (1998) for more details in this regard.

\section{Saudi Context}

Reviewing the related literature, it is quite clear that there is lack of research investigating parental involvement and teaching quality within Saudi context, despite some attention that has been paid to this issue in the neighbouring areas, including Kuwait (Al-Shammari and Yawkey 2008), though this study focused on the role of involvement of parents of children with special needs. Such paucity of research gives the current work unique significance in that it tackles a new topic as far as Saudi context is concerned. Additionally, what makes the current work of paramount importance is the nature of the Saudi context. KSA is well-known for its conservative community which places certain restrictions on any man-women interaction. Male parents are disallowed to get involved in their daughters' learning, and the same extends to female parents as far as their son's learning is concerned. Additionally, local people in KSA are less familiar with their educational roles which might impinge on their chances to get involved in their children's learning. Additionally, there are no studies that addressed this issue in peripheral cities such as Hail (see Al-Shamari 2015a,b,c, 2016, Al-Shamari 2016, Jarrah and Zibin 2016a,b for recent studies on some aspects on Haili Arabic)

\section{Conclusion}

In this section, I discussed the main findings and assumptions posited for the related literature on the parental involvement. Firstly, I discussed the definition of parental involvement. Secondly, I discussed a brief historical background of parental involvement with special reference to its status in the UK. Thirdly, I discussed the effectiveness of parental involvement in the learning process in addition to the factors that encourage parents to get involved in their 
children's education and its importance. Fourthly, I investigated the counterarguments advanced against parental involvement and when it becomes negative, most notably overparenting. Fifthly, this section discussed the barriers that prevent parents from getting involved in their children's education, including the parent and family factors, child's age, learning difficulties and disabilities, behaviour problems of the children and the asocial factors, such as poverty. In the last section of this paper, I discussed the school-relayed factors that affect parental involvement like the school culture as well as the location of the school.

\section{References}

Abdul-Adil, J. K., \& Farmer Jr, A. D. (2006). Inner-city African American parental involvement in elementary schools: Getting beyond urban legends of apathy. School Psychology Quarterly, 21(1), 1. https://doi.org/10.1521/scpq.2006.21.1.1

Alhaisoni, E., Jarrah, M.A., \& Shehadeh, M.S. (2012). An investigation of evidentiality in the Arabic language. International Journal of Linguistics, 4(2), 260-273.

Al-Jarrah, R.S., Abu Dalu, A.M., \& Jarrah, M. (2015). A relevance-theoretical account of three Arabic pragmatic operators of concession in a political discourse. Lodz Papers in Pragmatics, 11(1), 51-76. https://doi.org/10.1515/lpp-2015-0004

Alshamari, (2016c), In Favor of Contrastive Topic Phrase in North Hail Arabic Left Periphery: Evidence from the Discourse Particle Tara. Newcastle And Northumbria Working Papers In Linguistics Volume, 22, 23.

Alshamari, M. (201b5). Documentation of Discourse-related Particles in North Hail Arabic. English Linguistics Research, 4(4), 44.

Alshamari, M.R., \& Jarrah, M. (2016). A Minimalist-Based Approach to Phrasal Verb Movement in North Hail Arabic. International Journal of English Linguistics, 6(1), 24. https://doi.org/10.5539/ijel.v6n1p24

Alshamari, M.R. (2015a). 1 A Relevance-Theoretical Account of Three Discourse Markers in North Hail Arabic. Studies in Literature and Language, 11(1), 6-15.

Anderson, K.J., \& Minke, K.M. (2007). Parent involvement in education: Toward an understanding of parents' decision making. The Journal of Educational Research, 100(5), 311-323. https://doi.org/10.3200/JOER.100.5.311-323

Atkins, L., \& Wallace. (2012). Qualitative Research in Education. London: Sage

Chapple, C. L., McQuillan, J. A., \& Berdahl, T. A. (2005). Gender, social bonds, and delinquency: A comparison of boys' and girls' models. Social Science Research, 34(2), 357-383. https://doi.org/10.1016/j.ssresearch.2004.04.003

Cohen, J., \& Brown, M. (2016). Teaching quality across school settings. The New Educator, 12(2), 191-218. https://doi.org/10.1080/1547688X.2016.1156459 
Conteh, J., \& Kawashima, Y. (2008). Diversity in Family Involvement in Children's Learning in English Primary Schools: Culture, Language and Identity. English Teaching: Practice and Critique, 7(2), 113-125.

Dang, H. V. (2015). Parental Perspectives towards the Vocational Education Training Sector in Vietnam. Journal of Education and Vocational Research, 6(1), 37-51.

Desforges, C., \& Abouchaar, A. (2003). The impact of parental involvement, parental support and family education on pupil achievement and adjustment: A literature review (Vol. 433). Nottingham: DfES Publications.

Desforges, C., \& Abouchaar, A. (2003). The impact of parental involvement, parental support and family education on pupil achievement and adjustment: A review of literature. London: DfES Publications.

Domina, T. (2005). Leveling the home advantage: Assessing the effectiveness of parental involvement in elementary school. Sociology of education, 78(3), 233-249. https://doi.org/10.1177/003804070507800303

Driessen, G., Smit, F., \& Sleegers, P. (2005). Parental involvement and educational achievement. British educational research journal, 31(4), 509-532. https://doi.org/10.1080/01411920500148713

Edwards, C. P., \& Kutaka, T. S. (2015). Diverse perspectives of parents, diverse concepts of parent involvement and participation: Contrasts between Italy and the United States.

El Nokali, N. E., Bachman, H. J., \& Votruba - Drzal, E. (2010). Parent involvement and children's academic and social development in elementary school. Child development, 81(3), 988-1005. https://doi.org/10.1111/j.1467-8624.2010.01447.x

Fan, X. (2001). Parental involvement and students' academic achievement: A growth modeling analysis. The Journal of Experimental Education, 70(1), 27-61. https://doi.org/10.1080/00220970109599497

Fan, X., \& Chen, M. (2001). Parental involvement and students' academic achievement: A meta-analysis. Educational psychology review, 13(1), 1-22. https://doi.org/10.1023/A:1009048817385

Felder, R. M., \& Brent, R. (1999). How to improve teaching quality. Quality Management Journal, 6, 9-21.

Garst, B. A., \& Gagnon, R. J. (2015). Exploring Overparenting within the Context of Youth Development Programs. Feature Articles Exploring Overparenting within the Context of Youth Development Programs, 6. https://doi.org/10.5195/jyd.2015.416

Gezani, B. P. (2009). The need for parent involvement in developing a learning culture in Hlanganani South. University of South Africa, Pretoria.

Goodall, J., \& Vorhaus, J. (2011). Review of best practice in parental engagement. Education, (6), 1144-1159. 
Grolnick, W. S., Benjet, C., Kurowski, C. O., \& Apostoleris, N. H. (1997). Predictors of parent involvement in children's schooling. Journal of educational psychology, 89(3), 538. https://doi.org/10.1037/0022-0663.89.3.538

Grolnick, W.S., \& Slowiaczek, M.L. (1994). Parents' involvement in children's schooling: A multidimensional conceptualization and motivational model. Child development, 65(1), 237-252. https://doi.org/10.2307/1131378

Hallgarten, J. (2000). Parents Exist, Ok!?: Issues and Visions for Parent-School Relationships. Institute for Public Policy Research.

Hammouri, Y.M., Jarrah, M.A., \& Khawaldeh, S.K. (2013). Intertextuality as a tool to determine syntax. International Journal of Linguistics, 5(2), 209. https://doi.org/10.5296/ijl.v5i2.3583

Harris, A., \& Goodall, J. (2006). Parental involvement in education: an overview of the literature. University of Warwick, Coventry.

Harris, A., Andrew-Power, K., \& Goodall, J. (2009). Do parents know they matter?: raising achievement through parental engagement. A\&C Black.

Hiatt, D. B. (1994). Parent involvement in American public schools: An historical perspective 1642-1994. The School Community Journal, 4(2), 27-38.

Hill, N. E., \& Taylor, L. C. (2004). Parental school involvement and children's academic achievement pragmatics and issues. Current directions in psychological science, 13(4), 161-164. https://doi.org/10.1111/j.0963-7214.2004.00298.x

Hoover-Dempsey, K. V., Bassler, O. C., \& Brissie, J. S. (1987). Parent involvement: Contributions of teacher efficacy, school socioeconomic status, and other school characteristics. American Educational Research Journal, 24(3), 417-435. https://doi.org/10.3102/00028312024003417

Hoover-Dempsey, K. V., Battiato, A. C., Walker, J. M., Reed, R. P., DeJong, J. M., \& Jones, K. P. (2001). Parental involvement in homework. Educational psychologist, 36(3), 195-209. https://doi.org/10.1207/S15326985EP3603_5

Hoover - Dempsey, K. V., Walker, J. M., Sandler, H. M., Whetsel, D., Green, C. L., Wilkins, A. S., \& Closson, K. (2005). Why do parents become involved? Research findings and implications. The Elementary School Journal, 106(2), 105-130. https://doi.org/10.1086/499194

Hoover-Dempsey, K., \& Sander, H. (1995). Parental involvement in children's education: Why does it make a difference. The Teachers College Record, 97(2), 310-331.

Hornby, G. (2000). Improving parental involvement. A\&C Black.

Hornby, G. (2011). Parental involvement in childhood education: Building effective schoolfamily partnerships. Springer Science \& Business Media. https://doi.org/10.1007/978-14419-8379-4 
Hornby, G., \& Lafaele, R. (2011). Barriers to parental involvement in education: An explanatory model. Educational Review, 63(1), 37-52. https://doi.org/10.1080/00131911.2010.488049

Hornby, G., \& Witte, C. (2010). Parental involvement in secondary schools in New Zealand: Implications for school psychologists. School Psychology International, 31(5), 495-508. https://doi.org/10.1177/0143034310382611

Hornby, G., \& Lafaele, R. (2011). Barriers to parental involvement in education: An explanatory model. Educational Review, 63(1), 37-52. https://doi.org/10.1080/00131911.2010.488049

Huang, G.H.C., \& Mason, K.L. (2008). Motivations of parental involvement in children's learning: voices from urban African American families of preschoolers. Multicultural Education, 15(3), 20.

Huntsinger, C. S., \& Jose, P. E. (2009). Parental involvement in children's schooling: Different meanings in different cultures. Early Childhood Research Quarterly, 24(4), 398-410. https://doi.org/10.1016/j.ecresq.2009.07.006

Ingersoll, R., \& Kralik, J. M. (2004). Teaching Quality. Education Commission of the States.

Jarrah, M., \& Zibin, A., 2016a. On Definiteness and Information Trigger in Arabic. Advances in Language and Literary Studies, 7(2), 55-67.

Jarrah, M., \& Zibin, A. (2016b). Syntactic investigation of nunation in Haili Arabic. SKY Journal of Linguistics, 29, 39-62.

Jarrah, M.A., 2016. Explicit-implicit distinction: A review of related literature. Advances in Language and Literary Studies, 7(1), 175-184.

Oakes, J., Lipton, M., Anderson, L., \& Stillman, J. (2015). Teaching to change the world. Routle.

Shumow, L., \& Hiatt-Michael, D.B., 2010. Parental involvement at home. Promising practices to support family involvement in schools, 57-74.

Smit, F., 1993. Parental Involvement in Education. Institute for Applied Social Sciences, Publicity Director, Toernooiveld 5, Nijmegen, Postbus 9048, 6500 KJ Nijmegen, The Netherlands.

Taha, K., Jarrah, M.A., \& Al-Jarrah, R.S. (2014). The discoursal Arabic coordinating conjunction wa (and). International Journal of Linguistics, 6(4), 172. https://doi.org/10.5296/ijl.v6i4.4547

Wanke, A. A. (2008). Parental Involvement in children's education (Doctoral dissertation).

Watson, G. L., Sanders-Lawson, E. R., \& McNeal, L. (2012). Understanding Parental Involvement in American Public Education. International Journal of Humanities and Social Science, 2(19), 41-50. 
Whiting, L. S. (2008). Semi-structured interviews: guidance for novice researchers. Nursing Standard, 22(23), 35. https://doi.org/10.7748/ns2008.02.22.23.35.c6420

Wilder, S. (2014). Effects of parental involvement on academic achievement: a meta-synthesis. Educational Review, 66(3), 377-397. https://doi.org/10.1080/00131911.2013.780009

Williams, B., Williams, J., \& Ullman, A. (2002). Parental involvement in education. Research Report No 332. Queen's Printer 2002.

Note

Note 1. Some literature points to the fact that parents sometimes show their positive views indirectly (see, Alhaisoni et al 2012, Hammouri et al 2013, Taha et al 2014, Al-Jarrah et al 2015, Jarrah 2016 for further discussion on how indirect messages can be obtained)

\section{Copyright Disclaimer}

Copyright for this article is retained by the author(s), with first publication rights granted to the journal.

This is an open-access article distributed under the terms and conditions of the Creative Commons Attribution license (http://creativecommons.org/licenses/by/3.0/). 